\title{
Laparoscopic repair of traumatic intraperitoneal bladder rupture: Case report and review of the literature
}

\author{
Brian Kim, MD; Matthew Roberts, MD, MEd, FRCSC
}

University of Ottawa, Division of Urology, The Ottawa Hospital, Ottawa, ON

Cite as: Can Urol Assoc J 2012;6(6):E270-E273. http://dx.doi.org/10.5489/cuaj.11237

\section{Abstract}

We present a case of intraperitoneal bladder rupture in a 42-yearold man repaired by a laparoscopic approach. Details of the case and a description of the operative procedure are outlined. We also review the literature on laparoscopic repair of traumatic bladder rupture.

\section{Case report}

A 42-year-old man presented to the emergency department with generalized abdominal pain and urinary retention. He had been binge-drinking alcohol and "passed out" while at home, and awoke several hours later with severe abdominal pain and an inability to void. A Foley catheter was inserted without difficulty and the urinary effluent revealed gross hematuria. Computed tomography (CT) scan of the abdomen and pelvis demonstrated a moderate amount of intraperitoneal free fluid, without any detectable intra-abdominal organ injury. He was emergently transferred to our tertiary-level care facility, and the urology team was notified to see this patient for consultation and management for suspected bladder trauma.

On initial assessment, the patient had normal vital signs, a moderate level of generalized abdominal tenderness, particularly in the suprapubic region, and no rebound tenderness. A Foley catheter was in situ and draining a mild degree of gross hematuria with no visible clots. Digital rectal examination revealed a normal-riding, non-tender, benign prostate gland.

On further questioning, there was no reported history of trauma, such as a fall, although the patient was unsure given his level of intoxication. He had no prior urological history or complaints. Laboratory investigations, including complete blood count (CBC) and creatinine, were within normal limits. A conventional cystogram was performed and did not demonstrate a bladder injury. However, drainage films were unfortunately not done (Fig. 1). Due to a high degree of suspicion, a CT cystogram was conducted which confirmed a small intraperitoneal rupture at the dome of the bladder (Fig. 2).

The patient was taken to the operating room emergently and consented to undergo an attempted laparoscopic primary bladder repair, with the possibility of an open repair.

\section{Procedure}

The procedure was performed with the patient under general anesthesia in supine position with steep Trendelenberg. Antibiotics were administered perioperatively. Flexible cystoscopy revealed a single small defect at the dome of the bladder, consistent with findings on the CT cystogram. The bladder was otherwise normal. An 18-French Foley catheter was placed and connected to a sterile saline irrigationdrainage system using a " $\mathrm{Y}$ "-connector.

A 2-cm supra-umbilical curvilinear incision was then made, and access into the peritoneal cavity was achieved with a 10-mm optical trocar. The abdomen was insufflated with carbon-dioxide gas to a pressure of $15 \mathrm{mmHg}$.

The abdomen was explored and there was a moderate amount of amber free fluid in the dependent portion of the pelvis. There was no pus or fecal contents. There was an obvious defect at the dome of the bladder measuring about $2 \mathrm{~cm}$. The surrounding bladder tissue was moderately inflamed but not devitalized. There were no other abdominal injuries apparent to the bowels, liver or spleen.

Two 5-mm working ports were placed in the right and left lower quadrants, about one handbreadth lateral to the umbilicus and $3 \mathrm{~cm}$ caudally. The bladder defect was closed full-thickness in a continuous fashion with a \#2-0 absorb- 


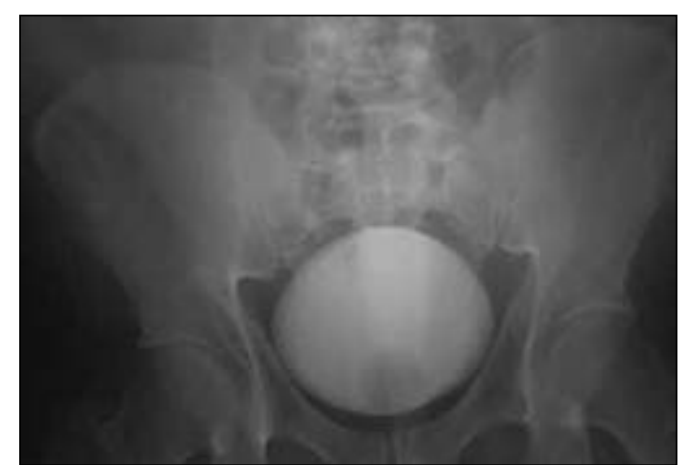

Fig. 1. A conventional cystogram (anteroposterior view) shows no clear evidence of bladder injury with the bladder filled with contrast. A drainage film was unfortunately not performed.

able, synthetic, braided suture (glycolide/lactide copolymer) pre-cut to about $15 \mathrm{~cm}$ in length. After filling the bladder with sterile water through the Foley catheter, a small area of leakage on the lateral edge of the suture line was identified and sutured with an interrupted stitch. Successful closure was confirmed by the absence of leakage on filling the bladder to capacity a second time. A Jackson-Pratt drain was placed through the right-sided port and brought down into the pelvis with a laparoscopic grasper.

\section{Follow-up}

The patient had an uncomplicated recovery and was discharged on postoperative day two with an indwelling Foley catheter. The Jackson-Pratt drain showed no evidence of urine leak and was removed prior to hospital discharge. A cystogram was repeated on postoperative day 14 and revealed an intact bladder (Fig. 3). The catheter was therefore removed and oral antibiotics were prescribed.

\section{Discussion}

Rupture of the urinary bladder typically occurs secondary to either blunt or penetrating trauma, although cases have been reported secondary to chronic bladder disease, bladder outlet obstruction and idiopathic causes. ${ }^{1}$ Intraperitoneal ruptures occur in patients with a full bladder and are less likely to be associated with major trauma in comparison to extraperitoneal ruptures. In our case, bladder rupture likely occurred due to bladder over-distension in a patient who was intoxicated. A minor trauma may have occurred, although the patient was unable to recall all of the recent events.

Suspected bladder injuries can be diagnosed by cystography, either conventional or CT. A properly performed cystogram involves maximally filling the bladder, or instilling at least $300 \mathrm{~mL}$, with contrast and obtaining anteroposterior and oblique radiographs if the patient can be safely turned.

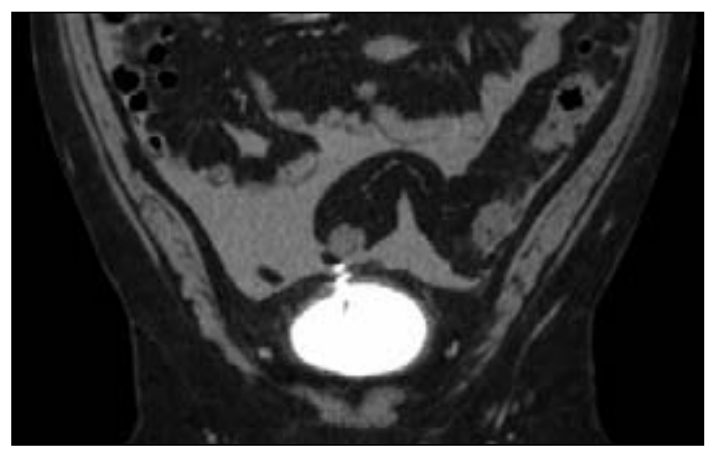

Fig. 2. A computed tomography cystogram (coronal view) reveals a perforation at the bladder dome, as well as urinary ascites.

Post-drainage films are essential to identify injuries that may be masked from a distended bladder. In comparison, CT cystography is performed with diluted contrast (about 3\%) and a post-drainage film is not required. Similar to conventional cystography though, contrast media should be instilled into the bladder in a retrograde fashion. Antegrade filling with a clamped catheter is inadequate and often leads to misdiagnosis.

A contemporary study by Quagliano and colleagues compared conventional versus CT cystography. ${ }^{2}$ They reported equivalent sensitivity and specificity, $95 \%$ and $100 \%$, respectively, for both modalities. These authors recommend that CT cystography be incorporated as part of the screening abdominal/pelvic CT in the setting of blunt torso trauma with suspected bladder injury, thus eliminating the need for a conventional cystogram.

As standard practice, intraperitoneal bladder injuries require immediate surgical intervention as they can lead to chemical peritonitis and are less likely to heal with catheter drainage alone. In some circumstances however, an initial conservative approach may be taken. Osman and colleagues described four isolated intraperitoneal bladder injuries in children that resolved with catheter drainage alone, and thus, avoided the need for surgical repair. ${ }^{3}$ This has also been described in other earlier case reports. ${ }^{4,5}$

When surgery is required, it has traditionally been accom-

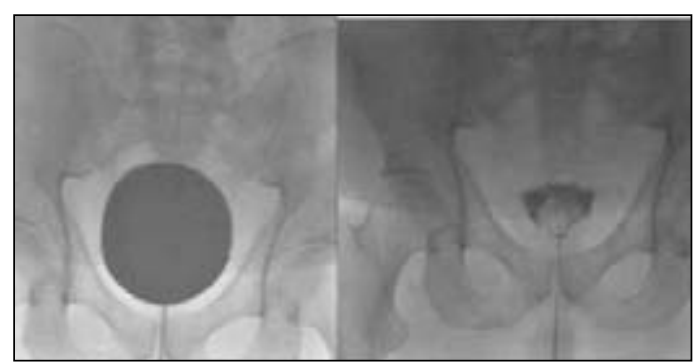

Fig. 3. A follow-up conventional cystogram confirms an intact bladder on both filling and drainage films (anteroposterior views). 


\begin{tabular}{|c|c|c|c|c|c|c|c|}
\hline Author & No. patients & $\begin{array}{l}\text { Mechanism(s) } \\
\text { of injury }\end{array}$ & $\begin{array}{c}\text { Size of } \\
\text { defect }(\mathbf{c m})\end{array}$ & $\begin{array}{l}\text { Location of } \\
\text { bladder defect }\end{array}$ & $\begin{array}{l}\text { Length of hospital } \\
\text { stay (days) }\end{array}$ & $\begin{array}{c}\text { Type of closure/ } \\
\text { suture }\end{array}$ & $\begin{array}{l}\text { Perioperative } \\
\text { complications }\end{array}$ \\
\hline Wirth et al. ${ }^{6}$ & $5(\mathrm{I})$ & NS & NS & NS & NS & NS & $\begin{array}{c}\text { One case } \\
\text { converted to open } \\
\text { due to discovered } \\
\text { bowel injuries }\end{array}$ \\
\hline Kim et al. ${ }^{7}$ & $6(\mathrm{I})$ & $\begin{array}{l}\text { Blunt trauma } \\
\text { (MVA, fall) }\end{array}$ & 6.4 (avg.) & NS & NS & $\begin{array}{l}\text { Single-layer } \\
\text { (continuous)/ } \\
\text { 3-0 polyglactin } \\
\text { suture }\end{array}$ & None \\
\hline $\begin{array}{l}\text { Maheswari } \\
\text { et al. }{ }^{8}\end{array}$ & 1 (I) & Idiopathic & 2.5 & Superior (dome) & 3 & $\begin{array}{l}\text { Two-layer } \\
\text { (continuous, } \\
\text { interrupted)/ } \\
\text { 3-0 polyglycolic } \\
\text { acid suture }\end{array}$ & None \\
\hline Golab et al. ${ }^{9}$ & $4(I)$ & $\begin{array}{l}\text { latrogenic } \\
\text { (TURBT) }\end{array}$ & $\begin{array}{l}0.5-1.5 \\
\text { (range) }\end{array}$ & NS & 3-5 (range) & $\begin{array}{c}\text { Single-layer } \\
\text { (interrupted)/ } \\
\text { 3-0 polyglactin } \\
\text { suture }\end{array}$ & None \\
\hline Matsui et al. ${ }^{10}$ & $1(\mathrm{C})$ & $\begin{array}{l}\text { Blunt trauma } \\
\text { (fall) }\end{array}$ & 1.5 & Superior (dome) & 12 & $\begin{array}{c}\text { Two-layer } \\
\text { (interrupted)/ } \\
\text { 3-0 polyglactin } \\
\text { suture }\end{array}$ & None \\
\hline Cottam et al. ${ }^{11}$ & 1 (I) & $\begin{array}{l}\text { Blunt trauma } \\
\text { (MVA) }\end{array}$ & 4 & Superior (dome) & 2 & $\begin{array}{c}\text { Two-layer/Suture } \\
\text { NS }\end{array}$ & None \\
\hline Iselin et al. ${ }^{12}$ & 1 (I) & $\begin{array}{l}\text { Blunt trauma } \\
\text { (fall) }\end{array}$ & $7-8$ & Posterior & 4 & $\begin{array}{l}\text { Single-layer } \\
\text { (continuous)/ } \\
\text { 3-0 polyglycolic } \\
\text { acid suture }\end{array}$ & None \\
\hline Parra et al. ${ }^{13}$ & 1 (I) & $\begin{array}{l}\text { latrogenic } \\
\text { (bladder } \\
\text { biopsy) }\end{array}$ & $1-1.5$ & Postero-superior & 1 & $\begin{array}{c}\text { Two layer } \\
\text { (continuous)/ } \\
\text { 3-0 polyglycolic } \\
\text { acid suture }\end{array}$ & None \\
\hline
\end{tabular}

I: intraperitoneal; E: extraperitoneal; C: combined; NS: not specified; MVA: motor vehicle accident; TURBT: transurethral resection of bladder tumour.

plished by open repair. This becomes essential when there are other associated injuries. However, repair can occasionally be performed laparoscopically in isolated bladder injuries.

In addition to the presented case, there are about 20 cases in the literature that describe this approach (Table 1), the first of which was described by Parra and colleagues. ${ }^{6-13}$ The mechanisms of injury were either from blunt trauma or iatrogenic injury during cystoscopic bladder tumour biopsy or resection. All injuries were intraperitoneal and presumed to be isolated in hemodynamically stable patients. One case, described by Wirth and colleagues, was converted to an open repair when injured bowel was detected on initial exploratory laparoscopy. ${ }^{6}$ Bladder defect sizes were mostly small, but also repaired successfully in larger defects up to $8 \mathrm{~cm}$, and were located away from the trigone and ureters. ${ }^{12}$ The repairs were performed with absorbable suture with a single- or two-layer closure, either continuous or interrupted. Leakage was tested intra-operatively with bladder filling, occasionally with indigo carmine solution, and postoperatively with conventional cystography about 10 days later. Apart from the single case that required conversion as described above, there were no perioperative complications reported and hospital stays were relatively short. One patient remained in hospital for 12 days until his catheter was removed, but no extenuating reasons for prolonged admission were reported. ${ }^{10}$ Cystoscopy is not mandatory, as long as the bladder, especially the bladder neck, is explored during surgery.

Overall, laparoscopic repair of intraperitoneal bladder injuries is a favourable option in the carefully selected, stable patient who is able to undergo laparoscopic surgery. Injuries should be isolated and amenable to safe intracorporeal suturing, such as defects located away from the trigone and ureters. Benefits of this surgical approach likely include less postoperative pain, shorter hospital stay, quicker overall recovery and improved cosmesis.

\section{Conclusion}

We have described a case of successful laparoscopic repair of an intraperitoneal bladder rupture. This approach may be 
considered in select cases, such as in patients with isolated bladder injuries and who are otherwise stable. Potential advantages of laparoscopic repair are less operative morbidity to the patient and improved postoperative recovery.

Competing interests: None declared.

This paper has been peer-reviewed.

\section{References}

1. Brandes S, Borrelli J. Pelvic fracture and associated urologic injuries. World J Surg 2001;25:1578. http:// dx.doi.org/10.1007/s00268-001-0153-x

2. Quagliano PV, Delair SM, Malhotra AK. Diagnosis of blunt bladder injury: A prospective comparative study of computed tomography cystography and conventional retrograde cystography. J Trauma 2006;61:410-21. http://dx.doi.org/10.1097/01.ta.0000229940.36556.bf

3. Osman Y, El-Tabey N, Mohsen T, et al. Nonoperative treatment of isolated posttraumatic intraperitoneal bladder rupture in children - is it justified? J Urol 2005;173:955-7. http://dx.doi.org/10.1097/01. ju.0000152220.31603.dc

4. Mulkey AP, Witherington R. Conservative management of vesical rupture. Urology 1974:4:426-30 http://dx.doi.org/10.1016/0090-4295(74)90012-0
5. Richardson JR, Leadbetter GW. Non-operative treatment of the ruptured bladder. J Urol 1975;114:213-6.

6. Wirth GJ, Peter R, Poletti P, et al. Advances in the management of blunt traumatic bladder rupture: experience with 36 cases. BJU Int 2010;106:1344-9. http://dx.doi.org/10.1111/j.1464410X.2010.09377.x

7. Kim FJ, Chammas MF Jr, Gewehr EV, et al. Laparoscopic management of intraperitoneal bladder rupture secondary to blunt abdominal trauma using intracorporeal single layer suturing technique. J Trauma 2008;65:234-6. http://dx.doi.org/10.1097/TA.0b013e318169279e

8. Maheshwari PN, Bhandarkar DS, Shah RS. Laparoscopic repair of idiopathic perforation of urinary bladder. Surg Laparosc Endosc Percutan Tech 2005;15:246-8. http://dx.doi.org/10.1097/01. sle.0000174569.89172.a7

9. Gołab A, Stojewski $M$, Gliniewicz B, et al. Laparoscopy as a treatment for intraperitoneal bladder injury. Scand I Urol Nephrol 2003;37:339-41. http://dx.doi.org/10.1080/00365590310014779

10. Matsui Y, Ohara H, Ichioka K, et al. Traumatic bladder rupture managed successfully by laparoscopic surgery. Int J Urol 2003;10:278-80. http://dx.doi.org/10.1046/i.1442-2042.2003.00610.x

11. Cottam D, Gorecki PJ, Curvelo $M$, et al. Laparoscopic repair of traumatic perforation of the urinary bladder. Surg Endosc 2001;15:1488-9.

12. Iselin CE, Rohner $S$, Tuchschmid $Y$, et al. Laparoscopic repair of traumatic intraperitoneal bladder rupture. Urol Int 1996;57:119-21. http://dx.doi.org/10.1159/000282893

13. Parra RO. Laparoscopic repair of intraperitoneal bladder perforation. J Urol 1994;151:1003-5.

Correspondence: Dr. Brian Kim, The Ottawa Hospital, Civic Campus, Division of Urology, B2, 1053 Carling Ave., Ottawa, ON KIY 4E9; brkim@toh.on.co 